\title{
New Perspectives on Dystonia
}

\author{
Mélanie Langlois, Francois Richer, Sylvain Chouinard
}

\begin{abstract}
Dystonia is a syndrome of sustained muscular contractions with numerous underlying etiologies. This review examines the varied phenomenology of dystonias, its evolving classification including recent genetic data as well as its clinical investigation and treatment. Although age of onset, anatomical distribution and family history are key elements of the investigation of dystonia, classification increasingly relies on etiologic and genetic criteria. Physiological abnormalities in striatocortical circuits are common in dystonia but the pathophysiology is still unclear. In recent years, a great deal has been learned on the more common primary dystonias such as primary torsion dystonia and on dystonia-plus syndromes such as dopamine responsive dystonia. Treatment of dystonia has also evolved and there are now a number of therapeutic agents with clear beneficial effects including anticholinergics, benzodiazepines, and botulinum toxin and there is growing interest in neurofunctional surgery including deep brain stimulation.
\end{abstract}

RÉSUMÉ: Nouvelles perspectives sur la dystonie. La dystonie est un syndrome comportant des contractions musculaires soutenues et ayant une étiologie variée. Cette revue examine le spectre phénoménologique des dystonies, les changements dans la classification compte tenu des données génétiques récentes, ainsi que l'investigation clinique et le traitement. Bien que l'âge de début, la distribution anatomique et l'histoire familiale soient des éléments clés de l'investigation de la dystonie, on tient compte de plus en plus de critères étiologiques et génétiques dans la classification des dystones. Des anomalies physiologiques des circuits striato-corticaux sont fréquentes dans la dystonie. Cependant, la physiopathologie demeure obscure. Au cours des dernières années, on a acquis beaucoup de connaissances sur les dystonies primaires plus courantes telles la dystonie idiopathique de torsion et les syndromes "dystonie plus" comme la dystonie sensible à la dopa. Le traitement de la dystonie a également évolué et il existe maintenant un certain nombre d'agents thérapeutiques ayant des effets bénéfiques incontestables comme les anticholinergiques, les benzodiazépines et la toxine botulique et on observe un intérêt croissant pour la chirurgie neurofonctionnelle, dont la stimulation profonde du cerveau.

Can. J. Neurol. Sci. 2003; 30: Suppl. 1 - S34-S44

Dystonia is a syndrome of sustained muscle contractions, frequently causing twisting and repetitive movements or abnormal postures. ${ }^{1}$ Since the first descriptions of dystonia at the beginning of the 20th century by Oppenheim, ${ }^{2}$ the nomenclature and classification of dystonia have evolved in relation with our understanding of the clinical spectrum and multiple causes of this syndrome. This article provides an overview of the phenomenology, epidemiology, classification, etiologies, pathophysiology, investigation and treatment of dystonia.

\section{Phenomenology}

The term dystonia describes a syndrome and not a disease, as numerous etiologies can give rise to similar patterns of sustained contractions. Dystonia is one of the most difficult movement disorders to recognize. Because of the high variability in the speed of contractions, it can sometimes be confused with chorea, tremor or even myoclonus. Also, because of its varied expression, it is not unusual for a patient with dystonia to be diagnosed as having a psychogenic movement disorder. Some distinguishing clinical features of dystonia can help the diagnosis. The direction of the contraction is almost always consistent ${ }^{3}$ and there is continual involvement of the same muscle group. Also, dystonia usually becomes evident during movement (action dystonia), and the causal movement may be nonspecific or extremely task-specific (occupational dystonia). A unique feature of dystonia is that the abnormal movements are influenced by the position of the affected body part. A dystonic movement can disappear if the body part is placed in a null position. This last finding is important in the differential diagnosis of myoclonus, chorea and tremor as those involuntary movements can not be stopped by changing body position.

Another characteristic of dystonic movements is that they can be reduced by sensory tricks (geste antagoniste). These generally

From the Unité des Troubles du Mouvement André-Barbeau, Centre Hospitalier de l'Université de Montréal, Montreal, QC, Canada.

Reprint requests to: Sylvain Chouinard, Unité des Troubles du Mouvement, HotelDieu du CHUM, Pav. Jeanne-Mance, bureau 7561, 3840 St-Urbain, Montreal, QC, Canada, H2W1T8 
consist of tactile, proprioceptive or other sensory modulators used by the patient. Touching the involved body part or an adjacent one can often reduce the muscle contraction. The mechanism of the geste antagoniste is unknown, but it is likely that sensory stimulation may modulate presynaptic inhibition so as to improve the reciprocal inhibition and the co-contraction of agonist and antagonist muscles. ${ }^{4}$ As is the case in many movement disorders, dystonia is exacerbated by anxiety or fatigue, reduced by relaxation or hypnosis and suppressed during deep sleep. ${ }^{5}$

Two types of tremors can be associated with dystonia: (1) a postural/action tremor that resembles essential tremor and (2) a rhythmic expression of rapid dystonic movements. In contrast to other forms of tremor, dystonic tremor will usually appear only when the affected body part is placed in a position of opposition to the major direction of pulling. Dystonic tremor also appears to be less regular than essential tremor. However, it is sometimes very difficult to distinguish between the two types of tremor, especially in cervical tremor. Dystonic tremor can also be associated with myoclonus. ${ }^{6}$

\section{EPIDEMIOLOGY}

A recent epidemiological survey of dystonia has shown that dystonia is the third most prevalent movement disorder after Parkinson's disease (PD) and Essential Tremor. ${ }^{7}$ However, since dystonia can have so many etiologies, the true prevalence is unknown. For primary dystonia, one study, estimated the prevalence to be 3.4 per 100,000 for generalized dystonia and 29.5 per 100,000 for focal dystonia. ${ }^{8}$ There are ethnic differences in prevalence, with childhood and adolescent-onset primary dystonia being more common in Jews of Eastern European or Ashkenazi ancestry.

\section{Classification OF DYSTONIA}

Dystonia is classified according to age of onset, body distribution (Table 1) or etiology (Table 2) and, more recently, genetic criteria, such as the pattern of inheritance or the disease locus, have refined the classification ${ }^{9}$ (Table 3 ).

Age of onset is a useful prognostic factor in primary dystonia. The younger the dystonia begins, the more likely it will become generalized, and the older the age of onset, the more likely it will remain focal.

When dystonia is classified according to body distribution (see Table 1), it can be described as focal, segmental, multifocal or generalized. As with age of onset, the first site of dystonia has a prognostic value. In patients with onset in the legs, $90 \%$ will develop symptoms in other parts of the body and their symptoms are also more likely to evolve into generalized dystonia. ${ }^{10}$ In contrast, only a minority of those whose symptoms begin in the cervical region will have a spread to other body parts. Hemidystonia is almost always symptomatic regardless of its age of onset. ${ }^{11}$

\section{Classification by body distribution \\ Blepharospasm}

Blepharospasm is a bilateral, synchronous, forceful, involuntary contraction of the orbicularis oculi muscles, causing repetitive blinking (clonic spasms) or more sustained closure of
Table 1: Classification of dystonia by distribution

A. Focal: involvement of one body part

1. Eyelids: blepharospasm

2. Mouth: oromandibular dystonia, embouchure dystonia

3. Larynx: dystonic adductor dysphonia or whispering dysphonia

4. Neck: cervical dystonia

5. Hand and arm: writer's cramp, occupational dystonia, musician's dystonia, yips

B. Segmental: involvement of two or more contiguous body parts

1. Cranial: two or more parts of cranial and neck musculature affected

2. Axial: neck and trunk affected

3. Brachial: one arm and axial; both arms, + /- neck, $+/$ - trunk

4. Crural: one leg and trunk; both legs, + /- trunk

C. Multifocal

1. Two or more non-contiguous parts affected

D. Generalized

1. Combination of segmental crural dystonia in combination with any other segment

E. Hemidystonia

1. Ipsilateral arm and leg affected

Adapted from Németh AH. The genetics of primary dystonias and related disorders. Brain 2002; 125: 695-721.

the eyelids (tonic spasms). In severe cases, tonic closure of the eyes can cause functional blindness. More frequent in women, it usually occurs around the sixth decade. ${ }^{12}$ It is often accompanied by dystonic movements of adjacent muscles such as the eyebrows and the paranasal muscles. In many patients, it is preceded by a sensation of eye irritation or photophobia and it may begin unilaterally. Watching television, reading, driving, fatigue and exposure to bright light commonly aggravate the spasm, while concentration, relaxation and certain sensory tricks (touching the eyelids, talking, etc.) may act as geste antagoniste. Spasms may remain focal or spread to the oromandibular area, a segmental form of dystonia referred to as Meige syndrome.

\section{Oromandibular dystonia}

Oromandibular dystonic spasms may occur in the region of the jaw, lower face or mouth. Included are spasms of jaw opening or closing, jaw deviation, lip smacking, tongue protrusion, or minor twitching of the oral region. In isolation, oromandibular dystonia is a relatively uncommon form of focal dystonia and it is often part of a segmental dystonia.

\section{Spasmodic dysphonia}

Spasmodic dysphonia involves dystonic spasms of the laryngeal muscles. It occurs most frequently in the forth or fifth decade and is more frequent in women. ${ }^{12}$ The most common form of dysphonia is the adductor type in which the voice is strained, high-pitched and commonly punctuated by repetitive brief interruptions of speech. Singing, whispering or changing pitch may reduce the spasms. Less commonly, abduction spasms 
Table 2: Classification by etiology

\section{A. Primary}

1. Early-onset primary torsion dystonia - PTD - DYT1 -TORY1A

2. Early-onset segmental cervical/cranial - DYT13

3. Whispering dysphonia - DYT4

4. Adult - onset familial torticollis - DYT7

5. Mixed - phenotype dystonia - DYT6

6. Sporadic, adult-onset focal dystonia
i. Blepharospasm
ii. Oro-mandibular dystonia
iii. Spasmodic dysphonia
iv. Cervical dystonic
v. Occupational dystonia
vi. Trunk dystonia
vii. Others

\section{B. Dystonia-plus syndromes}

1. Dystonia with parkinsonism

i. Dopa-responsive dystonia

1. DYT5-GTPcyclohydrolase 1 deficiency

2. Tyrosine hydroxylase deficiency

3. 6-pyruvoyltetrahydropterin synthase deficiency

4. Pterin-4a-carbinolamine dehydratase

5. Dihydropteridine reductase deficiency

ii. Dopamine-agonist responsive dystonia

1. Aromatic amino acid decarboxylase deficiency

iii. Rapid-onset dystonia -parkinsonism- DYT12

2. Dystonia with myoclonus

i. Dystonia-myoclonus- DYT11

\section{Secondary dystonia}

a) Perinatal cerebral injury

$\begin{array}{lll}\text { 1. Perinatal anoxia } & 2 \text {. Kernicterus } & 3 \text {. Delayed onset dystonia }\end{array}$

b) Congenital malformation

c) Infectious, postinfectious, inflammatory, and paraneoplastic

1. Reye's syndrome 2. Viral encephalitis 3. SSPE

4. Prion disease 5. Tuberculosis 6. Syphilis

7. Paraneoplastic brainstem encephalitis 8. Lupus

9. Antiphospholipid antibody syndrome

d) Head trauma, brain surgery

e) Thalamotomy

f) Cervical cord injury or lesion

g) Lumbar canal stenosis

h) Electrical injury

i) Peripheral injury

j) Brainstem lesion

k) Posterior fossa tumors

1) Central pontine myelinolysis

m) Focal cerebral vascular injury

n) Arteriovenous malformation

o) Hypoxia

p) Brain tumor

q) Multiple sclerosis

r) Drug induced
1. Levodopa,
2. Dopamine D2 receptor blocking
dopamine agonists (antipsychotics, metoclopramide)
3. Ergotism
4. Anticonvulsivants
5. Selective serotonin reuptake inhibitors
6. Buspirone
7. Cocaine
8. MAO inhibitors
9. Flecainide
1. Manganese 2. Carbon monoxide
3. Carbon disulfide
4. Cyanide
5. Methanol
7. 3-nitroproprionic acid
6. Disulfiram
8. Wasp sting

s) Toxic

t) Metabolic

1. Hypoparathyroidism
D. Heredodegenerative diseases

u) Trinucleotide repeat disorders

1. Huntington's disease

2. Machado-Joseph disease

3. Dentatorubropallidoluysiaan atrophy

4. Other spinocerebellar degenerations

v) Parkinsonian disorders

1. Parkinson's disease

2. Juvenile parkinsonism

3. Progressive supranuclear palsy

4. CBGD

5. Multiple system atrophy

6. DYT3

w) Lysosomal storage disorders

1. Metachromatic leukodystrophy

2. GM1 gangliosidosis

3. GM2 gangliosidosis

4. Nieman Pick C

5. Krabbe disease

6. Neuronal ceroid Lipofuscinosis

$\mathrm{x})$ Amino and organic acidurias

1. Glutaric acidemia type 1

2. Homocystinuria

3. Hartnup's disease

4. Methylmalonic aciduria

5. Fumarase deficiency

y) Mitochondrial disorders

1. Leigh's disease

2. Leber's hereditary optic neuropathy

3. Dystonia deafness/Mohr Tranenberg

z) Disorders of metal and mineral metabolism

1. Wilson's disease

2. Hallervorden-Spatz

3. Fahr's syndrome

aa) Miscellaneous metabolic disorders

1. Lesch-Nyhan syndrome

2. Molybdenum cofactor deficiency

3. Cokayne's disease

4. Triosephosphate isomerase deficiency

5. Ataxia telangiectasia

6. Guanidinoacee methyltransferase deficiency

7. Glucose transport defects

bb) Other disorders

1. Rett syndrome 2. Pelizaeus-Merzbacher disease

3. Vitamin E deficiency 4. Intraneuronal inclusion disease

5. Xeroderma pigmentosa 6. Neuroacanthocytosis/HARP syndrome

7. Familial striatal necrosis 8 . Infantile bilateral striatal necrosis

9. Progressive pallidal degeneration

10. Hereditary spastic paraplegia + dystonia

\section{E. Psychogenic dystonia}

PTD = primary distortion dystonia; $\mathrm{SSPE}=$ subacute sclerosing panencephalitis; CBGD = corticobasal ganglionic degeneration

Adapted from Fahn S, et al. Classification of dystonia. Advances in Neurology, vol 78, 1998, Friedman J, et al. Dystonia and its disorders. Neurologic clinics 2001; 19: 681705 and Fahn S. Dystonia: and Fahn S. Phenomenology, classification, etiology, genetics and pathology. A comprehensive review of movement disorders for the clinical practitioner. 11th annual course, 2001. 
Table 3: Genetic classification of dystonia

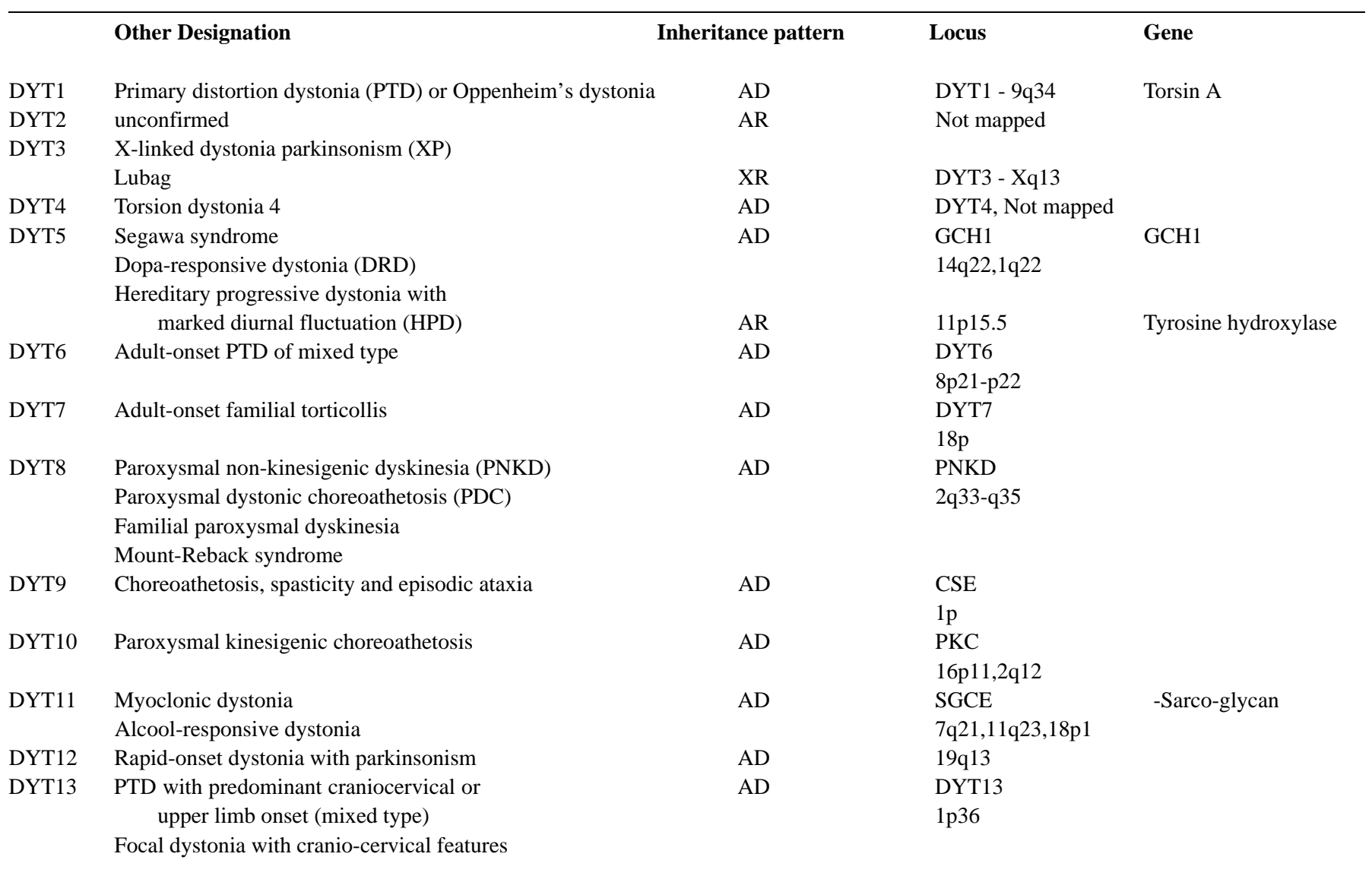

Adapted from Németh AH. The genetics of primary dystonias and related disorders. Brain 2002; 125: 695-721.

of the vocal chords give the voice a whispering, breathy character. Spasmodic dysphonia may also be mixed (adduction and abduction).

\section{Spasmodic torticollis (cervical dystonia)}

Cervical dystonia is the most common form of focal dystonia. More frequent in women, it can occur at any age but more frequently around $50 .{ }^{12}$ It involves involuntary contractions of the neck muscles causing a variety of abnormal movements and postures of the head. Referring to head position, torticollis may be described as predominantly rotational (the most common type), laterocollis, retrocollis, flexion, tilting, elevation of shoulder or complex. The tremulous type is often confused with essential tremor. In some patients, the dystonic jerks may be rhythmic and produce a jerky type of tremor unlike the smaller amplitude tremor observed in patients with essential tremor. With time, abnormal posturing will be superimposed on or replace the rhythmic jerking. Neck pain occurs in $70-80 \%$ of patients ${ }^{13}$ and usually responds well to botulinum toxin (BTX) injections. Cervical dystonia spreads segmentally in some patients ${ }^{13}$ but it rarely becomes generalized. ${ }^{14}$ Spontaneous remissions are observed in $10-20 \%$ of patients but are usually not sustained. ${ }^{12}$

\section{Limb dystonia}

Limb dystonia, such as writer's cramp, often begins as taskspecific action dystonia. Unlike other focal dystonias, incidence is the same in both sexes. ${ }^{12}$ It begins usually between $20-50$ years of age. In those patients, writing will bring involuntary, often painful contractions of upper limb muscles. In some cases, writing may become illegible. Other examples of task-specific dystonias include musician's cramp such as hand dystonia with piano playing or guitar picking, lip and tongue dystonia (embouchure dystonia) with playing brass or woodwind instruments, typist's cramp, golfer's yips, and card dealer's hand dystonia.

\section{Trunk dystonia}

In extremely rare cases, dystonia could be localized to the trunk muscles. ${ }^{15}$

\section{Classification by etiology}

Dystonia may also be classified according to etiology (Table 2). One recent classification divided etiologies in four categories, ${ }^{16}$ primary dystonia, dystonia-plus syndrome, secondary dystonia and heredodegenerative diseases. Primary 
dystonia consists of familial and nonfamilial types. It is important to recognize that most primary dystonias are sporadic and the onset is generally in adulthood.

\section{A. Primary dystonia (Table 2)}

This classification is likely to change as our knowledge of the genetic basis of dystonias increases.

\section{Early-onset primary torsion dystonia (PTD, Oppenheim's} dystonia, TORIA, DYT1)

Primary torsion dystonia (PTD) was the first type of dystonia described by Oppenheim. The prevalence has been reported to be five to ten times higher in Ashkenazi Jews than in the non-Jewish population. ${ }^{17}$ Transmission is autosomal dominant (penetrance between $30-40 \%$ ) in both Jewish and non-Jewish groups. The gene has been mapped to chromosome $9(9 \mathrm{q} 32-34)^{18}$ and is the result of a deletion of one of a pair of GAG triplets in the ATPbinding protein, torsin A. ${ }^{9}$

Torsin A is a heat shock protein widely distributed in the normal adult brain, with an important expression within the substantia nigra pars compacta, which suggests a role in dopaminergic modulation. ${ }^{19}$ Some evidence suggests that mutant torsin A may lead to abnormalities in dopamine vesicle formation. $^{20}$ Also markers of post-synaptic dopamine transmission suggest an increase in dopamine turnover within the striatum in DYT1. ${ }^{21}$

Primary torsion dystonia can also be caused by de novo GAG deletion events. ${ }^{22}$ The GAG deletion accounts for almost all mutations in torsin A. ${ }^{9}$ However, a minority of patients with typical torsion dystonia do not have a mutation in torsin $\mathrm{A}$, suggesting the presence of other loci. ${ }^{18,23,24}$

Primary torsion dystonia typically begins before 26 years of age, (mean age of onset 12.5 years). It often starts in a limb and spreads to other body parts, including trunk, neck and sometimes cranial muscles. ${ }^{3}$ A majority of patients will develop a multifocal or generalized dystonia. There is marked clinical variability in DYT1, ranging from children who are profoundly disabled to adults who are obligate carriers of the disease gene and have few or no symptoms of the condition. , $^{9,26}$

\section{Early-onset segmental cervical-cranial-DYT13}

This is another form of autosomal dominant primary dystonia (penetrance $<60 \%$ ). It was described in an Italian family with an average age of onset of 15 years. ${ }^{27}$ The craniocervical region is the most affected, however some patients developed generalized dystonia. A locus has been localized on chromosome 1p36.13$36.32 .^{27}$

\section{Whispering dysphonia - DYT4}

An Australian family was described ${ }^{28,29}$ in which linkage to 9q34 was excluded and it was given the locus designation DYT4. Onset varied between 13-37 years of age, transmission is autosomal dominant with complete penetrance in all examined obligate carriers, and most patients present with whispering dysphonia or torticollis. Most patients eventually developed generalized dystonia. ${ }^{9}$

\section{Adult-onset familial torticollis - DYT7}

A locus on chromosome $18 \mathrm{p}$ was mapped in a German family. The age of onset of symptoms was between 28 and 70 years. This dystonia has an autosomal dominant mode of inheritance, ${ }^{30}$ and the dystonia is usually limited to neck muscles (85\%) with occasional facial and arm involvement or spasmodic dysphonia.

\section{Mixed-phenotype dystonia - DYT6}

Linkage analysis in two Mennonite families mapped the gene to chromosome $8 \mathrm{p} 21-8 \mathrm{q} 22 .{ }^{31}$ To date, no gene mutations have been identified. Age at onset ranges from six to 38 years of age. ${ }^{32}$ In about half of patients, cervical or cranial muscles are involved first, with progression involving neck, speech or facial muscles. ${ }^{32}$

\section{Sporadic, usually adult-onset focal dystonia}

This is the most common form of primary dystonia. This form of dystonia is most likely to be focal and can progress to a segmental dystonia. Cervical dystonia is the most frequent primary dystonia, followed by dystonia affecting the cranial musculature such as blepharospasm, task-specific dystonia and spasmodic dysphonia. The role of genetics in adult-onset focal dystonia is not well-understood. One study has shown that as many as $25 \%$ of patients with focal dystonia have relatives with dystonia. ${ }^{32}$

\section{B. Dystonia-plus syndromes}

In this class of dystonia, associated clinical features are present including parkinsonism or myoclonus.

\section{Dystonia with parkinsonism}

- Dopa-responsive dystonia (DRD) - Segawa's SyndromeDYT5

The prevalence of DRD is difficult to estimate because of ascertainment problems. ${ }^{33}$ There is a female predominance of 23:1. Dopa-responsive dystonia is generally an autosomal dominant disorder with a low penetrance. It involves mutations in the GTP-cyclohydrolase (GTPCH) I gene (GCH1) on chromosome $14 \mathrm{q} \cdot{ }^{34}$ The GTPCH enzyme is involved in the synthesis of tetrahydrobiopterin, a cofactor of tyrosine hydroxylase, the rate-limiting enzyme of dopamine synthesis. ${ }^{20}$ In contrast to Parkinson's disease, striatal dopamine nerve terminals are preserved in GTPCH-deficient DRD. ${ }^{35}$

Dopa-responsive dystonia is genetically complex, as different families have different mutations on the GCH1 gene. Also, some families do not show a mutation in the GCH1 gene, suggesting the presence of other loci.

The symptoms of DRD are variable. ${ }^{9}$ Major symptoms are linked to striatal dopamine deficiency and they respond very well to a low dose of levodopa. A frequent presentation is a diurnal fluctuating dystonia starting in the legs of children usually between four to eight years of age. The dystonia can also involve the trunk and arms. Many patients have features of parkinsonism including rigidity, bradykinesia, flexed posture and postural instability. In approximately $25 \%$ of cases, there is also hyperreflexia, with ankle clonus, but plantar responses are flexion. Dorsiflexion of the big toe can be observed spontaneously or induced by exercise. This is often called the striatal toe. $^{36}$

Dopa-responsive dystonia can begin in infancy, and can resemble cerebral palsy. ${ }^{33}$ In adulthood, it can present as a focal dystonia of the arm, neck or cranium or as parkinsonism mimicking PD and limb dystonia that is diurnal and related to exercise. $^{33}$ 
The diagnosis of DRD depends on both the examination and the dramatic response with low doses of levodopa (less than 300 $\mathrm{mg}$ daily). ${ }^{37}$ Additionally, a decrease in the levels of homovanillic acid in the CSF is a pathognomonic finding. The most reliable laboratory examinations are levels of $\mathrm{GCH} 1$ activity in monocytes (less than $20 \%$ of normal) as well as neopterin and biopterin levels in the CSF. ${ }^{36}$ Decreased neopterin in CSF was shown to distinguish DRD from PD and other basal ganglia diseases. ${ }^{38}$

- Other dystonia-plus syndromes associated with parkinsonism

A number of other genetic abnormalities of cathecholamine biosynthesis can produce dystonia, including tyrosine hydroxylase deficiency, ${ }^{39,40}$ 6-pyruvoyltetrahydropterin synthase deficiency, ${ }^{41}$ sepiapterin reductase deficiency and dihydropterine reductase deficiency. ${ }^{42}$ Clinical features of four families with the mild form of tyrosine hydroxylase deficiency were similar to those of GTPCH-deficient DRD families. ${ }^{43}$ However, severe forms were described in nine other families with onset before six months, developmental motor and speech delay, truncal hypotonia, rigidity of extremities, hypokinesia, oculogyric crises, and ptosis. ${ }^{43} \mathrm{~A}$ similar clinical phenotype may be observed with defects in aromatic amino acid decarboxylase, which converts levodopa to dopamine. ${ }^{44}$

\section{- Rapid-onset dystonia-parkinsonism - DYT12}

This is a very rare condition, with autosomal dominant transmission and incomplete penetrance. Onset is variable and clinical features include dystonic spasms, bradykinesia, postural instability, dysarthria and dysphagia developing over a period of several hours to weeks. ${ }^{45} \mathrm{~A}$ locus has been localized to chromosome $19 q 13$ in two American families ${ }^{46}$ and in one Irish family. ${ }^{47}$

\section{Dystonia with myoclonus}

\section{- Myoclonus-dystonia - DYT11}

In this disorder, individuals have myoclonus, dystonia or both, and the two types of movements can affect different body regions. Myoclonus-dystonia has an autosomal dominant transmission pattern with incomplete penetrance. The clinical onset is variable from six months to 38 years. Most often the neck and arms are involved, and sometimes the trunk, the bulbar muscles and the legs. Often, alcohol reduces muscle jerks significantly. ${ }^{48}$ Most frequently, the disease appears to be slowly progressive for a few years after onset and then stabilizes. ${ }^{45}$

Recent genetic studies suggest that essential myoclonus and myoclonus-dystonia may be allelic disorders. ${ }^{9}$ Three regions have been associated with myoclonus-dystonia. First, a change in the D2 receptor on chromosome 11q23 was identified in two unrelated families. ${ }^{49,50}$ Another locus on chromosome $7 \mathrm{q} 21$ has been identified in numerous families. ${ }^{51}$ The gene responsible is $\varepsilon$-sarcoglycan, which is part of the dystrophin-glycoprotein complex. ${ }^{52}$ Recently, a third locus was mapped on chromosome 18 p11 haplotype in all 13 affected members of a large Canadian family. ${ }^{53}$

\section{Secondary dystonia}

Secondary dystonias arise from injuries or abnormalities of the nervous system. There is often an association with pathologic lesions, most involving basal ganglia particularly the putamen. ${ }^{54}$ Also, a lesion of the putamen is more likely to cause dystonia than any other form of movement disorder. ${ }^{55}$ Lesions in the thalamus, cortex, cerebellum, brainstem and spinal cord have also been reported to produce dystonia..$^{51,52,56-59}$ It is important to recognize that dystonia may appear long after the insult and may be progressive. ${ }^{44}$

\section{Heredodegenerative dystonia}

Some heredododegenerative disorders can also include dystonia as part of their clinical spectrum. Examples include early-onset PD, juvenile-onset heredodegenerative dystonia, Wilson's disease, DYT3 (X-linked dystonia-parkinsonism, Lubag), etc.

\section{Pathophysiology}

The major characteristic of dystonic movements is the presence of sustained co-contractions of agonist and antagonist muscles. Impairment of voluntary movements usually follows from these co-contractions and also from impaired activation of the appropriate agonist muscles, as well as from a spread of contractions to more distant muscles not required for the task.

No consistent morphological abnormalities have been observed in the brains of patients with primary dystonia. The cerebral structures most often involved in dystonia include the basal ganglia especially the putamen, as well as the thalamus, and premotor cortex..$^{54,55,59,60}$ However, brainstem, spinal cord and peripheral nerve lesions have also been implicated. ${ }^{56}$ Some cases have shown modifications in the locus ceruleus, substantia nigra pars compacta, pedunculopontine nucleus, and dorsal raphe nucleus, but others have not. ${ }^{56}$ Recently, frozen brain specimen from three patients with adult-onset primary dystonia revealed an increase in levels of copper and manganese in the globus pallidus, putamen and thalamus. ${ }^{57}$

Several studies suggest that there is a loss of D2 receptors in the putamen in dystonia, ${ }^{60,61}$ but the significance of this finding is not yet clear. However, dystonia is clearly associated with several changes in neuronal activity in striatal circuits. The available electrophysiological data from patients suggest that dystonia (at least for primary and some secondary dystonia) involves alterations in the rate, pattern, somatosensory responsiveness and synchronization of neural activity in pallidothalamo-cortical circuits. ${ }^{62}$ However, the exact relationship between changes in neural activity in these regions and the development of dystonia remains unclear. ${ }^{63}$

The mean discharge rate in globus pallidus internus (GPi) is decreased in dystonia, ${ }^{64-68}$ which suggests that the inhibitory output from the direct pathway is increased. In addition decreased globus pallidus externus activity and increased subthalamic nucleus activity may alter the spatio-temporal characteristics of GPi output ${ }^{62}$ and these changes may play a role in the development of dystonia. ${ }^{62}$ There is also evidence of uncontrolled changes in synchronization of neuronal populations in $\mathrm{GPi}^{66}$ which may interfere with voluntary modulation or produce involuntary movements. Changes in excitatory and inhibitory input to subthalamic nucleus and GPi and temporal fluctuations in synaptic inputs have been proposed to underlie the irregular neuronal activity observed in these patients. ${ }^{69,70}$

At least for primary dystonia, changes in neuronal activity 
from the pallidum to the brainstem and cortex may account for the observed changes in brainstem reflexes, whereas altered brainstem and cortical activity produced by changes in pallidal activity may lead to a disruption in the descending control of spinal systems and changes in spinal reflexes.

Ablation of the GPi can relieve dystonia, particularly primary dystonia, but the reasons for this effect are unclear. ${ }^{71-73}$ Disruption of abnormal firing patterns may produce the beneficial effects of pallidotomy. However, the improvement in dystonia after pallidotomy and pallidal deep brain stimulation (DBS), suggests that the thalamus, cortex, brainstem, and spinal cord are not the source of dysfunction in primary dystonia. Indeed, these regions appear to function relatively normally when the effects of abnormal basal ganglia activity are removed. ${ }^{62}$

Dystonia is linked to disrupted cortical motor function. Some have found increased premotor cortex activation using positron emission tomography ${ }^{74,75}$ but multiple and complex cortical changes are likely. Studies using transcranial magnetic stimulation suggest impaired cortical inhibition of motor activity. ${ }^{76}$ For many years, the basal ganglia have been thought to play a role in movement selection, the activation of one movement pattern and simultaneous inhibition of other patterns. Impaired cortical inhibition may lead to the loss of inhibition to spinal and brainstem reflexes which may result in a loss of scaling and focusing of muscle activity during movement. ${ }^{62}$ Inhibition is critical in many aspects of dystonia, but primarily in reciprocal agonist-antagonist interactions, and in the surround inhibition of portions of the body adjacent to the moving part. ${ }^{77,78}$ Surround inhibition is an important mechanism in motor control and it may be a major function of the basal ganglia. ${ }^{78} \mathrm{~A}$ study by Tinazzi et $\mathrm{al}^{79}$ shows that the inhibitory integration of afferent inputs, mainly proprioceptive inputs, coming from adjacent body parts is abnormal in dystonia. The capacity of cortical neurons to respond correctly to afferent activity is altered. This inefficient integration could give rise to an abnormal motor output and may thus contribute to dystonia. Widened receptive fields in the pallidum and thalamus may contribute to the inability of dystonic patients to selectively activate specific muscle groups by defocusing sensory input from the periphery to the sensorimotor cortex. ${ }^{62}$

\section{INVESTIGATION OF DYSTONIA}

Initial evaluation should focus on a good history, including drug exposure and detailed family history. Most cases of primary and secondary hereditary dystonia have a gradual onset, while cases of acquired secondary dystonias may be more acute or subacute. ${ }^{80}$ Physical examination is aimed at identifying other neurological signs that will suggest an etiology other than primary dystonia.

For patients who appear to have a primary dystonia, the extent of the investigation will vary according to age of onset and clinical presentation. As a general rule, isolated dystonia presenting in adulthood without any other neurological sign is most likely to be a primary dystonia and the work-up could be kept to a minimum. Brain imaging and cervical MRI should be done as various structural lesions can present with focal dystonia. $^{14}$ Neck radiography may be useful for excluding cervical spine abnormalities as a cause of abnormal neck posture not related to muscle contraction ("pseudodystonia"). ${ }^{81}$

In the evaluation of primary adult onset focal dystonia, present guidelines do not recommend genetic testing for DYT1, unless a clear family history is present. ${ }^{82}$ Genetic testing for the DYT1 mutation and counselling should be done in all those with onset before the age of 26 years with any site of onset, and is also warranted if onset is later and the patients have a relative with early-onset symptoms. ${ }^{82}$

Wilson's disease should always be ruled out with serum ceruloplasmin and slip lamp examination, in all patients with age of onset before 50 years, as this disease is treatable. For patients presenting dystonia accompanied by other neurological findings with the exception of tremor, a more complete investigation is needed.

\section{TreatMent}

A small minority of patients with symptomatic dystonia can benefit from a specific treatment. This is the case for Wilson's disease, drug-induced dystonia, DRD, or psychogenic dystonia. For other patients, the goal of treatment is to control the symptoms rather than the cause.

Symptomatic treatment will vary according to the distribution of dystonia. For patients with generalized, multifocal and sometimes segmental dystonia, pharmacotherapy will be offered. In contrast, the majority of patients with focal dystonia will benefit the most from BTX injection. Symptomatic dystonia tends to respond less well to pharmacotherapy. All patients with dystonia starting in childhood should receive a trial of levodopa/carbidopa which is highly effective in DRD (DYT5) and other disorders affecting dopamine synthesis.

If dopaminergic agents are ineffective, anticholinergics should be tried because $40-50 \%$ will respond at least moderately. ${ }^{83,84}$ Except for DRD, anticholinergic drugs are the most efficacious treatment for dystonia. We recommend starting with $2.5 \mathrm{mg}$ of trihexyphenidyl (artane) and increasing by $2.5 \mathrm{mg}$ every week until improvement or side effects prevent further increase. Some patients may require up to $100-120 \mathrm{mg} /$ day. Most often, the limiting factor will be the development of side effects including confusion, memory loss, hallucinations, dry mouth, urinary retention and blurred vision. Kemadrin is another anticholinergic that can be used, starting at $2.5 \mathrm{mg}$ per day and increased to a usual dosage of 10-30 mg daily. ${ }^{80}$

Baclofen is less helpful than anticholinergics, but a good response has been seen in children. ${ }^{81-85}$ The starting dose is $10 \mathrm{mg}$ at bedtime, increasing the dose by $10 \mathrm{mg}$ each week to a maximum of $30 \mathrm{mg}$ three or four times daily. ${ }^{80}$ The main side effects include drowsiness, confusion, and dizziness.

Other drugs can also be tried including benzodiazepines such as clonazepam starting with $0.25 \mathrm{mg}$ at bedtime and gradually increasing the dosage to a maximum of $1 \mathrm{mg}$ four times daily. ${ }^{80}$ Tetrabenazine, a dopamine depleting drug, is particularly efficacious in patients with tardive dystonia. Dopamine antagonists, such as haloperidol, are often effective but can eventually worsen the dystonia or cause tardive dyskinesia ${ }^{80}$ and are not recommended. Although clozapine has been recommended for the treatment of tardive dystonia, ${ }^{86}$ the initial data on the use of these agents in treating idiopathic dystonia 
have not been promising. ${ }^{87}$ The role of other atypical antidopaminergics in treating dystonia has not been fully established. ${ }^{88}$ Recently mexiletine has been found to be effective in cervical dystonia. ${ }^{89}$

If medication trials fail, BTX injections can be tried in well chosen muscles in patients with generalized dystonia in association with other treatments. For patients with focal dystonia, BTX injection is the treatment of choice for cervical dystonia, blepharospasm, jaw dystonia, spasmodic dysphonia ${ }^{90,91}$ and to a lesser extent in limb dystonia. In patients with cervical dystonia, BTX is injected into neck muscles and improvement is usually seen in $80-90 \%$ of patients. ${ }^{80}$ Blepharospasm requires injection of botulinum toxin type A (BTXA) into the orbicularis oculi muscles surrounding the eye. Benefit usually occurs in at least $85-95 \%$ of patients. ${ }^{80}$ Adductor spasmodic dysphonia patients are given BTXA injections into the vocal cords. Improvement is usually seen in $90-95 \%$ of patients. ${ }^{80}$ For jaw-closing dystonia, BTX is injected into the masseter, temporalis or internal pterygoid muscles whereas the digastric and external pterygoid muscles are injected for jawopening dystonia. Patients with writer's cramp and limb dystonia can also benefit from injections tailored to their symptoms. ${ }^{80}$ Electromyography may be useful in some patients to guide the selection of the muscles to be treated and to determine the injection site and dosing of BTX. ${ }^{92}$

Botulinum toxin injections produce chemodenervation and local muscle paralysis. The therapeutic effect is due to its action at the neuromuscular junction which causes an inhibition of the release of acetylcholine from the nerve terminals and muscle paralysis. Also, the injection appears to improve reciprocal inhibition by altering tonic sensory inflow through muscle afferents. ${ }^{93}$ Additionally, one group studied intracortical inhibition with transcranial magnetic stimulation in patients with upper limb dystonia before and after the injection of BTXAand show that BTX transiently alters cortical excitability. ${ }^{94}$ The duration of the effects of BTX injection is variable depending on the conditions and the amount injected. However, on average the effect of an injection lasts 10-14 weeks.

There are two groups of patients that could be resistant to BTX. ${ }^{95}$ Causes of primary nonresponse include long-standing disease with contracture, insufficient dosage, injection of the incorrect muscles, complex pattern of muscle involvement or other technical factors. Causes of secondary failure include change in the pattern of muscle activity or the development of neutralizing antibodies. Resistance associated with blocking antibodies could occur after repeated injections of BTX in 5-10\% of cases. ${ }^{96}$ Risks are higher with the use of booster injections, if short intervals between treatments and high doses are used. We suspect that the new form of BTXA, with lower protein load, will induce less resistance.

In addition to BTXA, six other serotypes of BTX (type B to G), are produced by different species of C. botulinum. ${ }^{97}$ The light chain of BTX types A and E targets the cytoplasmic protein SNAP- $25^{98}$ whereas toxin B targets vesicle-associated membrane protein (VMAP)/synaptobrevin. ${ }^{99}$

The efficacy of BTX type B in cervical dystonia has been shown in placebo-controlled trials. ${ }^{92,93}$ This efficacy was also found in patients with BTXA resistance. The most common adverse events reported in those trials were dry mouth and dysphagia. Actually there is no clinical comparisons available between both serotypes.

Although there are no known absolute contra-indications to BTX injection, relative contra-indications include pregnancy, lactation, disorders of neuromuscular transmission, motor neuron disease, and concurrent use of aminoglycosides. ${ }^{100}$ It is usually a safe treatment as there are no systemic side effects. Dysphagia, neck weakness and local pain at the injection site are the most commonly reported side effects, but dizziness, dry mouth, a flu-like syndrome, lethargy, dysphonia and generalized weakness have been reported. ${ }^{95}$ These side effects are always transient. Dysphagia most often occurs because of local spreading of the toxin with injections of the sternocleidomastoid. ${ }^{101}$

Intrathecal baclofen may be useful in selected patients, particularly those with secondary dystonia and spasticity. ${ }^{102}$ To date, its role as a possible treatment for dystonia has been reported in approximately 50 patients and the conclusion is that intrathecal baclofen is not as effective in dystonia as it is in spasticity. ${ }^{103}$

As a last resort, surgery should also be considered. The main indications for stereotactic surgery are generalized dystonia progressing to severe disability or life-threatening stage and severe motor impairment or pain resulting from hemidystonia or segmental dystonia. ${ }^{104}$

Thalamotomy, the first intracranial surgical intervention for dystonia, was often highly effective but associated with a high incidence of complications when done bilaterally, including impairment of speech and swallowing. The best results have been found in patients with involvement of the distal portion of one or two limbs, absent dystonia in trunk or neck, and idiopathic, nonprogressive disease. ${ }^{105}$

There are several case reports of dramatic improvement in generalized dystonia after bilateral pallidotomy. ${ }^{63,68,69,106,107}$ Overall, authors have suggested that the more the preoperative brain images are normal, the better the outcome after pallidal surgery. ${ }^{108}$ However, the risk of recurrence of dystonia following ablative surgery may not be low even in DYT1 patients. ${ }^{109}$

Pallidal stimulation has been favored recently as an alternative to pallidotomy. ${ }^{104}$ The argument in favour of DBS is the possibility of bilateral intervention with an acceptable morbidity rate. ${ }^{110}$ Another argument that favours DBS is its reversibility. ${ }^{111}$ In a series of seven individuals with DYT1, including six children, stimulation of the globus pallidus was effective in $90.3 \%$ of cases. ${ }^{112}$ Patients showed improvement in pain within days, more gradual improvement in dystonia over three months, and this was maintained for at least one year. Recently, pallidal stimulation has been tried for cervical dystonia. Several groups have described a significant pain reduction and motor benefit in patients treated for severe cervical dystonia. ${ }^{113-115}$ For secondary generalized dystonia, results are highly variable, ranging from no benefit at all to significant improvement in some cases. ${ }^{104}$ Deep brain stimulation is still an investigational treatment ${ }^{104}$ and reserved for patients for whom other therapies have failed.

Selective denervation has been used for a long time in focal dystonia. ${ }^{116,117}$ Procedures that can be performed include myotomy, microvascular decompression, spinal accessory nerve (SAN) section, ventral rhizotomy combined with SAN section, 
and selective dorsal ramisectomy combined with SAN section (also known as selective peripheral denervation). The most commonly performed surgical procedure consists of selective section of dorsal rami of the upper cervical nerves sometimes combined with selective SAN section or anterior rhizotomy. There are no controlled trials on the effectiveness of denervation and most of the results from series of patients are retrospective. Several open-label and uncontrolled studies have yielded response rates ranging from $48-89 \% .^{110-118}$

With the introduction of BTX, selective peripheral denervation is usually performed when BTX injection fails, or resistance develops. Patients who have marked cervical spine degenerative disease do poorly after selective denervation. ${ }^{119}$ It is therefore recommended that cervical spine imaging be part of the preoperative assessment. ${ }^{20}$ Complications include almost universal sensory loss over the distribution of the greater occipital nerve. In addition, patients may complain of dysphagia, occipital neuralgia, and hyperesthesia. ${ }^{118}$ Sometimes patients may need more than one intervention.

Behaviour modification therapy, sensory feedback therapy, and supportive psychotherapy have shown beneficial effects in some patients. ${ }^{120}$ Physical therapy and well-fitted braces can improve posture and prevent contractures, they may also be used as a substitute for sensory tricks. ${ }^{121}$ Recently, prolonged immobilization for occupational dystonia showed encouraging results in some patients ${ }^{122}$ as well as sensory training in patients with focal hand dystonia. ${ }^{123}$

\section{REFERENCES}

1. Fahn S, Marsden CD, Calne DB. Classification and investigation of dystonia. In: Marsden CD, Fahn S, (Eds). Movement Disorders. London, Butterworths, 1987;332-358.

2. Oppenheim H. Uber eine eigenartige Krampfkrankheit des kindlichen und jugendlichen alters (dysbasia lordotica progressiva, dystonia musculorum deformans). Neurol Centrabl 1911; 30: 1090-1107.

3. Bressman SB. Dystonia update. Clin Neuropharm 2000;23: 239-251.

4. Madhusudanan M. Dystonia: emerging concepts in pathophysiology. Neurol India 1999; 47: 263-267.

5. Fish DR, Sawyers D, Allen PJ, et al. The effect of sleep on the dyskinetic movements in Parkinson's disease, Gilles de la tourette syndrome, Huntington disease, and torsion dystonia. Arch Neurol 1991; 48:210-214.

6. Jedynack CP, Bonnet AM, Agid Y.Tremor and idiopathic dystonia. Mov Disord 1991; 6: 230-236.

7. Butler AG. An epidemiological survey of dystonia within the entire population of North East England over the past nine years. Fourth International Dystonia Symposium 2002, Atlanta, Georgia USA.

8. Nutt JG, Muenter MD, Aronson A, et al. Epidemiology of focal and generalized dystonia in Rochester, Minnesota. Mov Disord 1988; 3: 188-194.

9. Németh AH. The genetics of primary dystonias and related disorders. Brain 2002; 125: 695-721.

10. Greene P, Kang UJ, Fahn S. Spread of symptoms in idiopathic torsion dystonia. Mov Dis 1995;10:143-152.

11. Marsden CD, Obeso JA, Zarranz JJ, Lang AE. The anatomical basis of symptomatic hemidystonia. Brain 1985; 108: 463-483.

12. Tranchant C. Dystonies focales: aspects cliniques, étiologiques et thérapeutiques. Rev Neurol (Paris) 2000; 156: 1087-1094.

13. Stacy M. Idiopathic cervical dystonia: an overview. Neurology 2000; 55 (Suppl 5): S2-S8.

14. Dauer WT, Burke RE, Greene P, Fahn S. Current concepts on the clinical features, aetiology and management of idiopathic cervical dystonia. Brain 1998; 121: 547-560.
15. Bhatia KP, Quinn NP, Marsden CD. Clinical features and natural history of axial predominant adult onset primary dystonia. J Neurol Neurosurg Psychiatry 1997; 63: 788-791.

16. Fahn S, Bressman SB, Marsden CD. Classification of dystonia. Dystonia 3: Advances in Neurology, vol. 78. Philadelphia: Lippincott-Raven Publishers, 1998.

17. Zilber N, Korczyn AD, Kahana E, Fried K, Alter M. Inheritance of idiopathic torsion dystonia among Jews. J Med Genet 1984; 21 : 13-20.

18. Ozelius LJ, Hewett JW, Page C, et al. The early-onset torsion dystonia gene (DYT1) encodes an ATPbinding protein. Nat Genet 1997; 17: 40-48.

19. Augood SJ, Martin DM, Ozelius LJ, et al. Distribution of the mRNAs encoding torsin A and torsin B in the normal adult brain. Ann Neurol 1999; 46: 761-769.

20. Misbahuddin A, Warner TT. Dystonia: an update on genetics and treatment. Curr Opin Neurol 2001; 14: 471-475.

21. Augood SJ. Biochemistry in Oppenheim's Dystonia. Fourth International Dystonia Symposium 2002, Atlanta, Georgia USA.

22. Klein C, Brin MF, de Leon D, et al. De novo mutations (GAG deletion) in DYT1 gene in two non-Jewish patients with earlyonset dystonia. Hum Mol Genet 1998; 7:1133-1136.

23. Ozelius LJ, Page CE, Klein C, et al. The TOR1A (DYT1) gene family and its role in early onset torsion dystonia. Genomics 1999; 62: 377-384

24. Valente EM, Warner TT, Jarman PR, et al. The role of DYT1 in primary torsion dystonia in Europe. Brain 1998; 121: 23352339.

25. Burke RE, Brin MF, Fahn S, Bressman SB, Moskowitz C. Analysis of the clinical course of non-Jewish, autosomal dominant torsion dystonia. Mov Disord 1986; 1: 163-178.

26. Marsden CD. Investigation of dystonia. Adv Neurol 1988; 50: $35-$ 44.

27. Valente EM, Bentivoglio AR, Cassetta E, et al. DYT13, a novel primary torsion dystonia locus, maps to chromosome $1 \mathrm{p} 36.13-$ 36.32 in an Italian family with cranialcervical or upper limb onset. Ann Neurol 2001; 49: 362-366.

28. Parker N. Hereditary whispering dysphonia. J Neurol Neurosurg Psychiatry 1985; 48: 218-224.

29. Ahmad F, Davis MB, Waddy HM, et al. Evidence for locus heterogeneity in autosomal dominant torsion dystonia. Genomics 1993; 15: 9-12.

30. Leube B, Doda R, Ratzlaff T, et al. Idiopathic torsion dystonia: assignment of a gene to chromosome 18p in a German family with adult-onset, autosomal inheritance and purely focal distribution. Hum Mol Genet 1996; 5: 1673-1677.

31. Almasy L, Bressman SB, Kramer PL, et al. Idiopathic torsion dystonia linked to chromosome 8 in two Mennonite families. Ann Neurol 1997; 42:670-673.

32. Waddy HM, Fletcher NA, Harding AE, et al. A genetic study of idiopathic focal dystonias. Ann Neurol 1991; 29: 320.

33. Nygaard TG. Dopa-responsive dystonia. Delineation of the clinical syndrome and clues to pathogenesis. Adv Neurol 1993; 60: $577-585$.

34. Ichinose $\mathrm{H}$, Ohye $\mathrm{T}$, Takahashi $\mathrm{E}$, et al. Hereditary progressive dystonia with marked diurnal variation caused by mutations in the GTPcyclohydrolase 1 gene. Nat Genet 1994; 8: 236-242.

35. Furukawa Y, Nygaard TG, Gütlich M, et al. Striatal biopterin and tyrosine hydroxylase protein reduction in dopa-responsive dystonia. Neurology 1999; 53: 1032-1041.

36. Segawa M. Hereditary progressive dystonia with marked diurnal fluctuation. Brain Dev 2000; 22: S65-S80.

37. Bressman SB, Greene PE. Dystonia. Curr Treat Options Neurol 2000; 2: 275-285.

38. Furukawa Y, Nishi K, Kondo T, et al. CSF biopterin levels and clinical features of patients with juvenile parkinsonism. Advances in Neurology, vol. 60. New York: Raven Press, 1993: 562-567.

39. Knappskog PM, Flatmark T, Mallet J, et al. Recessively inherited L-Dopa responsive dystonia caused by a point mutation $(\mathrm{Q} 381 \mathrm{~K})$ in the tyrosine hydroxylase gene. Hum Mol Genet 1995; 4: 1209-1212. 
40. Ludecke B, Knappskog PM, Clayton PT, et al. Recessively inherited L-Dopa-responsive parkinsonism in infancy caused by a point mutation (L205P) in the tyrosine hydroxylase gene. Hum Mol Genet 1996; 5: 1023-1028.

41. Hanihara $\mathrm{T}$, Inoue $\mathrm{K}$, Kawanishi $\mathrm{C}$, et al. 6-pyrovoyltetrahydropterin synthase deficiency with generalized dystonia and diurnal fluctuations of symptoms: a clinical molecular study. Mov Disord 1997; 12: 408-411.

42. Nomura Y, Uetake K, Yukishita S, et al. Dystonia responding to levodopa and failure in biopterin metabolism. Adv Neurol 1998; 78: 253.

43. Furukawa Y. Dopa-responsive dystonia. Fourth International Dystonia Symposium 2002, Atlanta, Georgia USA.

44. Friedman J, Standaert DG. Dystonia and its disorders. Neurol Clin 2001; 19: 681-705.

45. Dobyns WB, Ozelius LJ, Kramer PL, et al. Rapid-onset dystoniaparkinsonism. Neurology 1993; 43:2596-2602.

46. Kramer PL, Mineta M, Klein C, et al. Rapid-onset dystoniaparkinsonism: linkage to chromosome 19q13. Ann Neurol 1999; 46: 176-182.

47. Pittock SJ, Joyce C, O'Keane V, et al. Rapid-onset dystoniaparkinsonism: a clinical and genetic analysis of a new kindred. Neurology 2000; 55: 991-995.

48. Gasser T. Inherited myoclonus-dystonia syndrome. Advances in Neurology, vol. 78. Philadelphia: Lippincott-Raven Publishers, 1998:325-334.

49. Klein C, Brin MF, Kramer P, et al. Association of a missense change in the D2 dopamine receptor with myoclonus dystonia. Proc Natl Acad Sci USA1999; 96: 5173-5176.

50. Garavagilia B, Invernizzi N, Nardocci N, et al. Molecular studies of childhood onset primary dystonias in Italy. Am J Hum Genet 2000; 67 (Suppl 2): 375.

51. Klein C, Schilling K, Saunders-Pullman RJ, et al. A major locus for myoclonus-dystonia maps to chromosome $7 \mathrm{q}$ in eight families. Am J Hum Genet 2000; 67: 1314.

52. Zimprich A, Grabowski M, Asmus F, et al. Mutations in the gene encoding epsilon-sarcoglycan cause myoclonus dystonia syndrome. Nat Genet 2001; 29: 66-69.

53. Grimes DA, Han F, Lang AE, et al. A novel locus for inherited myoclonus-dystonia on 18p11. Neurology 2002; 59: 1183-1186.

54. Burton K, Farrell K, Li D, et al. Lesions of the putamen and dystonia: CT and magnetic resonance imaging. Neurology 1984; 34: 962-965.

55. Bhatia K, Marsden CD. The behavioral and motor consequences of focal lesions of the basal ganglia in man. Brain 1994; 117: 859-876.

56. Zweig RM, Hedreen JC, Jankel WR, et al. Pathology in brainstem regions of individuals with primary dystonia. Neurology 1988; 38: 702-706.

57. Becker G, Berg D, Rausch WD, et al. Increased tissue copper and manganese content in the lentiform nucleus in primary adultonset dystonia. Ann Neurol 1999; 46: 260-263.

58. Naumann M, Becker G, Toyka KV, et al. Lenticular nucleus lesion in idiopathic torsion dystonia detected by transcranial sonography. Neurology 1996; 47: 1284-1290.

59. Lee MS, Marsden CD. Movement disorders following lesions of the thalamus or subthalamic region. Mov Disord 1994; 9: 493-507.

60. Perlmutter JS, Stambuck MK, Markham J, et al. Decreased F-18 spiperone binding in putamen in idiopathic focal dystonia. $\mathbf{J}$ Neuroscience 1997; 17: 843-850.

61. Naumann M, Pirker W, Reiners K, et al. Imaging pre- and postsynaptic side of striatal dopaminergic synapses in idiopathic cervical dystonia: a SPECTstudy using I-123 epidepride and I123 beta-CIT. Movement Disorders 1998; 13: 319-323.

62. Vitek JL. Dystonia: a model based on electrophysiological recordings in the operating room. Fourth International Dystonia Symposium 2002, Atlanta, Georgia USA.

63. Vitek JL. Pathophysiology of dystonia: a neural model. Mov Disord 2002; 17: S49-S62.

64. Lozano AM, Kumar R, Gross RE, et al. Globus pallidus internus pallidotomy for generalized dystonia. Mov Disord 1997; 12: 865-870.
65. Lenz FA, Suarez JI, Metman LV, et al. Pallidal activity during dystonia: somatosensory reorganization and changes with severity. J Neurol Neurosurg Psychiatry 1998; 65: 767-770.

66. Vitek JL, Zhang J, Evatt ML, et al. Gpi pallidotomy for dystonia: clinical outcome and neuronal activity. In: Fahn S, (Ed). Advances in Neurology: Dystonia 3. Philadelphia: LippincottRaven, 1998: 211-219.

67. Vitek Jl, Chockkan V, Zhang JY, et al. Neuronal activity in the basal ganglia in patients with generalized dystonia and hemiballismus. Ann Neurol 1999; 46: 22-35.

68. Delong MR. Primate models of movement disorders of basal ganglia origin. Trends Neurosci 1990; 13: 281-285.

69. Hassani O-K, Mouroux M, Feger J. Increased subthalamic neuronal activity after nigral dopaminergic lesion independent of disinhibition by means of the globus pallidus. Neuroscience 1996; 72: 105-115.

70. van Vreeswijk C, Sompolinsky H. Chaos in neuronal networks with balanced excitatory and inhibitory activity. Science 1996; 274: 1724-1726.

71. Iacono RP, Kuniyoshi SM, Lonser RR, et al. Simultaneous bilateral pallidoansotomy for idiopathic dystonia musculorum deformans. Pediatr Neurol 1996; 14:145-148.

72. Lin JJ, Lin SZ, Lin GY, Chang DC, Lee CC. Application of bilateral sequential pallidotomy to treat a patient with generalized dystonia. Eur Neurol 1998; 40: 108-110.

73. Ondo WG, Desaloms JM, Jankovic J, Grossman RG. Pallidotomy for generalized dystonia. Mov Disord 1998; 13: 693-698.

74. Eidelberg D, Moeller JR, Ishikawa T, et al. The metabolic topography of idiopathic torsion dystonia. Brain 1995; 118: 1473-1484.

75. Magyar-Lehmann, Antonini A, Roelcke U, et al. Cerebral glucose metabolism in patients with spasmodic torticollis. Mov Disord 1997; 12: 704-708.

76. Ridding MC, Sheean G, Rothwell JC, Inzelberg R, Kujirai T Changes in the balance between motor cortical excitation and inhibition in focal, task specific dystonia. J Neurol Neurosurg Psychiatry 1995; 39:493-498.

77. Rothwell JC, Obeso JA, Day BL, Marsden CD. Pathophysiology of dystonias. Adv in Neurol 1983; 39: 851-863.

78. Hallett M. Dystonia: abnormal movements result from loss of inhibition. Fourth International Dystonia Symposium 2002, Atlanta, Georgia USA

79. Tinazzi M, Priori A, Bertolasi L, et al. Abnormal central integration of a dual somatosensory input in dystonia. Evidence for sensory overflow. Brain 2000; 123: 42-50.

80. Adler CH. Strategies for controlling dystonia. Postgrad Med 2000; 108: 151-160.

81. Caso Martinez J, Arranz L. Recurrent torticollis due to cervical osteochondroma. Case report and review of the literature. Ann Exp Pediatr 1998; 49: 177-178.

82. Bressman SB, Sabatti C, Raymond D, et al. The DYT1 phenotype and guidelines for diagnostic testing. Neurology 2000; 54: 1746-1752.

83. Burk RE, Fahn S, Marsden CD. Torsion dystonia: a double blind, prospective trial of high dosage trihexyphenidyl. Neurology 1986; 36: 160-164.

84. Greene PE, Shale H, Fahn S. Analysis of open-label trials in torsion dystonia using high dosages of anticholinergics and other drugs. Mov Disord 1988; 3: 46-60.

85. Greene PE, Fahn S. Baclofen in the treatment of idiopathic dystonia in children. Mov Disord 1992; 7: 48-52.

86. Van Harten PN, Kampuis DJ, Matroos GE. Use of clozapine in tardive dystonia. Prog Neuropsychopharmacol Biol Psychiat 1996; 20: 263-274

87. Thiel A, Dressler D, Kistel C, Ruther E. Clozapine treatment of spasmodic torticollis. Neurology 1994; 44: 957-958.

88. Simpson GM. The treatment of tardive dyskinesia and tardive dystonia. J Clin Psychiat 2000; 61 (suppl 4): 39-44.

89. Ohara S, Hayashi S, Momoi H, et al. Mexiletine in the treatment of spasmodic torticollis. Mov Disord 1998; 13: 934-940.

90. Brin MF, Blitzer A, Stewart C. Laryngeal dystonia (spasmodic dysphonia): observations of 901 patients and treatment with 
botulinum toxin. Adv Neurol 1998; 78: 237.

91. Jankovic J. Medical therapy and botulinum toxin in dystonia. Adv Neurol 1998; 78: 169-183.

92. Comella CL, Jankovic J, Brin MF. Use of botulinum toxin type A in the treatment of cervical dystonia. Neurology 2000; 55 (Suppl 5): S15-S21.

93. Priori A, Berardelli A, Merueri B. Physiological effects produced by botulinum toxin treatment in upper limb dystonia. Changes in reciprocal inhibition between forearm muscles. Brain 1995; 118: 801-807.

94. Gilio $\mathrm{F}$, Currà $\mathrm{A}$, Lorenzano $\mathrm{C}$, et al. Effects of botulinum toxin type A on intracortical inhibition in patients with dystonia. Ann Neurol 2000; 48: 20-26.

95. Dauer WT, Burke RE, Greene P, Fahn S. Current concepts on the clinical features, aetiology, and management of idiopathic cervical dystonia. Brain 1998; 121: 547-560.

96. Hanna PA, Jankovic J. Mouse bioassay versus Western blot assay for botulinum toxin antibodies: correlation with clinical response. Neurology 1998; 50: 1624-1629.

97. Oguma K, Fujinaga Y, Inoue K. Structure and function of clostridium botulinum toxins. Microbiol Immunol 1995; 39: 161-168.

98. Schiavo G, Santucci A, DasGupta BR, et al. Botulinum neurotoxins serotypes A and E cleave SNAP-25 at distinct COOH terminal peptide bonds. FEBS Lett 1993; 335: 99-103.

99. Schiavo G, Benefenati F, Poulain B, et al. Tetanus and botulinumB neurotoxins block neurotransmitter release by proteolytic cleavage of synaptobrevin. Nature 1992; 359: 832-835.

100. Adler $\mathrm{CH}$. Botulinum toxin treatment of movement disorders. Neurobase. 3rd ed. San Diego: Arbor Publishing, 1999.

101. Blackie JD, Lees AJ. Botulinum toxin treatment in spasmodic torticollis. J Neurol Neurosurg Psychiatry 1990; 53: 640-643.

102. Ford B, Green PE, Louis E, et al. Use of intrathecal baclofen in patients with dystonia. Arch Neurol 1996; 53: 1241-1246.

103. Ford B, Greene PE, Louis ED, et al. Intrathecal baclofen in the treatment of dystonia. Advances in Neurology, vol. 78. Philadelphia: Lippincott-Raven Publishers, 1998:199-210.

104. Volkmann J, Benecke R. Deep brain stimulation for dystonia: patient selection and evaluation. Mov Disord 2002; 17: S112S115.

105. Tasker RR, Doorly T, Yamashiro K. Thalamotomy in generalized dystonia. Adv Neurol 1988; 50: 615-631.

106. Lozano AM, Kumar R, Gross RE, et al. Globus pallidus internus pallidotomy for generalized dystonia. Mov Disord 1997; 12: 865-870.

107. Lai T, Lai JM, Grossman RG. Functional recovery after bilateral pallidotomy for the treatment of early onset primary generalized dystonia. Arch Phys Med Rehab 1999; 80: 1340-1342.

108. Khan F, Alkhani A, Hutchison W, et al. The response to pallidal surgery for dystonia is dependent on the etiology. Teaching course on functional stereotaxy for movement disorders. Meeting of the Movement Disorder Society, Barcelona 2000.

109. Nomura Y, Ikeuchi T, Tsuji S, Segawa M. Two phenotpes and anticipation observed in Japanese cases with early onset torsion dystonia - pathophysiological consideration. Brain Dev 2000; 22: S92-S101.

110. Pollak P, Benabid AL, Krack P, et al. Deep brain stimulation. In: Jankovic J, Tolosa E, (Eds). Parkinson's Disease and Movement Disorders. Baltimore: Williams and Wilkins, 1998:1085-1101.

111. Krack P, Vercueil L. Review of the functional surgical treatment of dystonia. Eur J Neurol 2001; 8: 389-399.

112. Coubes P, Roubertie A, Vayssiere N, et al. Treatment of DYT1generalized dystonia by stimulation of the internal globus pallidus. Lancet 2000; 355: 2220-2221.

113. Krauss JK, Pohle T, Weber S, et al. Bilateral stimulation of globus pallidus internus for treatment of cervical dystonia. Lancet 1999; 354: 837-838.

114. Islekel S, Zileli M, Zileli B. Unilateral pallidal stimulation in cervical dystonia. Stereotact Funct Neurosurg 1999; 72: 248252.

115. Andaluz N, Taha JM, Dalvi A. Bilateral pallidal deep brain stimulation for cervical and truncal dystonia. Neurology 2001; 57: 557-558.

116. Bertrand CM, Molina-Negro P. Selective peripheral denervation in 111 cases of spasmodic torticollis: rationale and results. Adv Neurol 1988; 50: 637-643.

117. Krauss JK, Toups EG, Jankovic J, et al. Symptomatic and functional outcome of surgical treatment of cervical dystonia. J Neurol Neurosurg Psychiatry 1997; 63: 642-648.

118. Adler CH, Kumar R. Pharmacological and surgical options for the treatment of cervical dystonia. Neurology 2000; 55 (Suppl 5): S9-S14.

119. Chawada SJ, Munchau A, Johnson D, et al. Pattern of premature degenerative changes of the cervical spine in patients with spasmodic torticollis and the impact on the outcome of selective peripheral denervation. J Neurol Neurosurg Psychiatry 2000; 68: 465-471

120. Das SK, Choudhary SS. A spectrum of dystonias-clinical features and update on management. JAPI 2000; 48: 622-630.

121. Jankovic J. Dystonia: medical therapy and botulinum toxin. Fourth International Dystonia Symposium 2002, Atlanta, Georgia USA.

122. Prior A, Pesenti A, Cappellari A, et al. Limb immobilization for the treatment of focal occupational dystonia. Neurology 2001;57:405-409.

123. Zeuner KE, Bara-Jimenez W, Noguchi PS, et al. Sensory training for patients with focal hand dystonia. Ann Neurol 2002; 51: 593-598. 